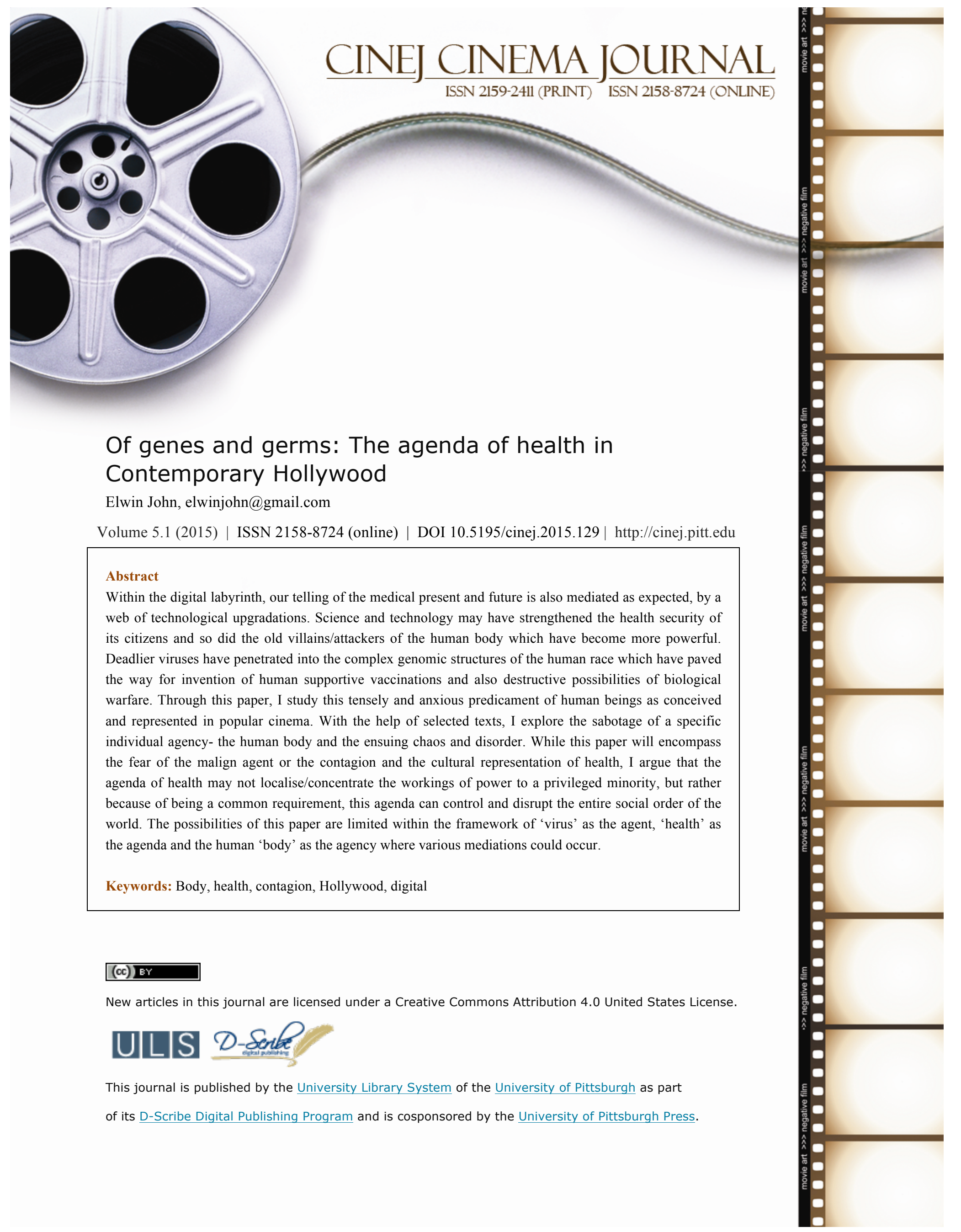




\section{Of genes and germs: The agenda of health in Contemporary Hollywood}

\section{Elwin John}

\section{'Health' in the Digital}

In our spontaneously transforming cultures, the advent of digital technology can be compared to the tip of an iceberg. Its offshoots like digital humanities and technologies of the body have explored the ways in which the human body can be re conceptualised and re constituted. This re- creation of the body calls our attention to the concept of 'health' as perceived through digital technologies. In many poorer parts of the world staying healthy still means to have at least one square meal per day. For some others, just by maintaining the natural state (diseaseless state) of the body, they are happy and satisfied to have a healthy state of the body. While for some others, the agenda of health seeks beyond the 'natural'. They improve their body mechanisms by augmentation. The possibilities of science and technology offer to enhance the natural state of the body. From wearing a pair of eye lenses to attaching a pacemaker to one's heart, we are enhancing the natural state of the body. Through cosmetic procedures, the body becomes more of plastic than of natural flesh and skin. Such bodies look flawless even when they question the humanness of the body.

The scientists at the Shanghai Second Medical University in 2003 successfully fused human cells with rabbit eggs. In 2004, researchers at the Mayo clinic in Minnesota created pigs with human blood flowing through their bodies (Mott). The Vacanti mouse has an extra ear that looks like human ear which was developed by seeding cow cartilage cells and they can be used as donor organs ("The Vacanti Mouse"). In such a scenario one should wonder at what point one can call the new form a human. Moreover if such combinations are to be developed further, 
what new human combinations are to be produced and for what purpose? These genetic human modifications are to be considered as an attempt to create 'complete' human forms. But whether the new forms will be completely human in the traditional sense is doubtful. Can the pigs with human blood flowing through its body be human? Or can they be even called pigs? So what exactly is the pig-ness of a pig? Questions like this will drag us back to the reconceptualisation of health in the midst of digital innovations. The examples cited above prove that scientists are experimenting to develop the perfect, complete and flawless human body.

Incompleteness of the body is also tackled by the hybridization of humans with artificial implants. In the case of a disabled body, it might limit itself to the attachment of different prostheses like pacemakers, steel rods, cochlear implants, artificial tooth, catheters, lenses etc. But it has to be deduced from these hybrid bodies that such implants are only making the person less powerful. Although intended to create complete beings, any prostheses will give a double identity to the person. As Cavallaro mentions in his The Body For Beginners it results in a better self and a failing self as it can "refine our capacities and remind us of our incapacities" (144).

There is nothing surprising about these activities as this is an era which is asking if the foetus has its rights or not. Considering an interesting case study done by John Frow in an article titled "Bodies in Pieces", I tend to believe that our's is a period that requires patenting of one's own genetic material. Surgical stealing of body organs like kidneys and other genetic information with commercial potentials without the consent of the patient justifies the significance for the creation of private property rights on one's own body. 
An extended form of such body modification can be observed in trans humanism. The attempt to develop a human nature which will adapt better and effectively to the technological and scientific knowledge is one among the dimensions of trans humanism. Human beings are redesigned in a lab with the help of certain radical enhancement techniques along with the combination of technologies such as memory enhancement drugs, life extension therapies, genetic engineering, bio-technology, fringe science etc. The hybridization of machine and human is drastically countered by Donna Haraway in her "A Cyborg Manifesto". The fictional world has already donated fully fledged cyborg models to us. Modern medicine is an extensive package of cyborg interventions. Humans are coupled with machines in every step of diagnosis and treatment. The realization that in the near future we will have more artificial body parts in a human body is the key idea behind the concept of cyborgs. At the moment, except for the brain and nervous system, every body part can be replaced. Thus 'humanness' might get reduced to just a brain in the body sometime in future. But brain alone cannot determine humanness is an acceptable suggestion.

Modern medical procedures are criticized for reducing the patient to a set of graphs, variables and constants. This set of results "reconstructs the patient as a clinical body in which the doctor therapeutically intervenes" (Nandy 156). The patient disappears during the various scanning processes and what is left is a history based on 'codes'. These codes enable the patient to be treated as a specimen in the laboratory. Thus this act of depersonalization makes the patient, a shadow patient. This idea of shadowiness can be contrasted to the digital technology's offshoots like Visible Human Project. Although both of them emerge from modern medicine, the visibility as opposed to shadowiness is interesting. The Visible Human Project enables us to see through the body via the human cadavers that are transformed into three dimensional visual 
data. But in both these projects there is a tendency for the human body to be regarded as a machine which is a cluster of numerous sub-systems.

Thus during the various attempts to improve the human condition, there is also a trivialization of the human identity. Whether it is about augmenting the human body or about attaining the myth of a perfect body, the concerns that are related to human identity and life are highly compromised. If the problems associated with aging, life span, other physical and cognitive limitations can be rectified with the help of technology, what makes us 'human' may not hold any meaning anymore. Technology will then gift humanity with evolved beings that are not completely 'human' in its traditional sense. Highly superior and highly intelligent beings will then revamp the existing theories of race.

Science and its offspring may have made our lives easier in some ways. It has also medicalized our everyday life and health is a concern that can even be checked within the comforts of one's own living room. Insulin pen, digital blood pressure apparatus, thermometer, pregnancy test strip etc are some of the medical test apparatuses that can be used from one's home. Medicalization of our everyday life also owes to the constant surveillance of our bodies. Our bodies are constantly checked for its defects both knowingly and unknowingly. In effect, we become consumers of 'health'. A new strategy employed in the ad campaigns of personal hygiene products is worth mentioning here. Personal healthcare indicates that good personal hygiene practices are essential to protect ourselves and others from getting sick. Certain kind of an individualised and customised agenda is put forth by bringing 'personal' or 'you' to the centre of these campaigns. It tries to advocate that good health of others is also in your hands. Thus these ad campaigns try to make us more responsible and concerned about the welfare of a 
larger group of people. I believe that this strategy of personalization is effective in selling personal hygiene products.

Sociology scholars Ian Shaw and Alan Alridge call medical professionals and health promoters as cultural entrepreneurs as they turn people into health consumers who consume various kinds of health lifestyles. This is partly a product of the commercialisation of health. Healthy lifestyle and its commercialization will immediately bring to the light the mushroom growth of fitness industry. As mentioned in the essay, "Cosumerism, Health and Social Order", "exercise bikes, treadmills and rowing machines are simulations of the real thing. It blurs the dualism inherent to modernism such as the self versus the body, inside versus outside, work versus leisure. To get one's body into shape can be a route to the enhancement of the self. It is also a sign of competence, self-control and self-discipline- attributes valued by the market" (Shaw 39). With a feel good agenda, health is packaged and commercialized in the consumer culture.

Coming to the Indian context, healthcare is still the privilege of a select group of people here. Unlike the western societies we do not go for regular check-ups or we do not take monthly dental appointments unless and until we really become ill. We lack methodical documentation of patients' medical histories, systematic insurance policies and the state is yet to chart out proper plans for healthcare measures. In spite of such deficiencies, Indian healthcare system is also not free from the clutches of commercialization of health. Doctors push for C-sections than a normal delivery as it can bring more income to the hospital. Cases of mass $\mathrm{C}$ - section in Kerala have been reported. Four doctors were reported to have conducted $21 \mathrm{C}$ - sections in a span of 48 hours in a government hospital in Alappuzha, Kerala. Although in the hands of a 
privileged group, the earlier mentioned fitness industry has found firm roots in India also. Maintenance of the body is slowly becoming a marker of one's personal identity.

Healthcare can also be extended to stand as a moral enterprise as it promotes ideas on how we should live our lives. Consider any of the toothpaste advertisements on television. Everybody knows that brushing twice a day will keep your teeth healthy and away from bacteria. But the advertisements are overtly dramatic, arousing panic and it makes you think that you commit a crime if you do not use that particular toothpaste. Such interventions into one's private life is criticised as the politicisation of the self through discourses of empowerment in Shaw's article.

The perils of 'health' in the 'digital' is reflected in the growing 'cyberchondria' (cyber+hypochondria: medical anxiety caused by self-diagnosis through reading and reviewing search results and literature online). On the other hand, telemedicine (provide clinical healthcare at a distance) has shown benefits especially to people living in rural and isolated regions where doctors and specialists are far away. But in such regions the installation of telecommunication equipment could be problematic. Virtual medical treatment might again decrease human interaction between doctor and patient, but it can be helpful in the treatment of infectious diseases.

Through this section of the paper I have traced the various mediations that occur through the medium of body for the attainment of good health. In effect we find that health itself is mediated in different levels of its deployment: in the definition of health (natural state, augmentation, enhancement etc), consumerism, commercialization, surveillance, medicalization etc. Health is one among the prime concerns of human life and its mediations in 
the digital crossroads are reflected in contemporary cinema. The following sections of this paper will expound this agenda of health via the agent of contagion/virus and the agency of body through select Hollywood cinema.

\section{Pathogen, Health and Social Order}

"The single biggest threat to man's continued dominance on planet is the virus" - Joshua Lederberg Ph.D, Nobel Laureate

Lawrence K Frank in his essay "What is social order?" suggests that "social order has long been conceived as an organization or mechanism which exists as a part of the cosmos and operates through large-scale forces acting at a distance" (470). It can be suggested that social ordering is the manner in which a society is organized on the basis of certain agencies and the rules and standards required to maintain the structures within a society. Steven Soderbergh's 2011 release medical thriller Contagion represents how a disruption within the agency of health can result in absolute social disorder. In the 1995 medical thriller Outbreak by Wolfgang Petersen, the killer virus initially hits a small village in Africa and later on spreads to the US.

In Contagion Soderbergh narrates the notions of public health during the time of a pandemic. This movie touches upon several themes and one among those is the massive panic among the citizens which goes out of control of the state. People could not comprehend what was happening for a long time as it took some time for the researchers to identify that the virus was transmitted through fomites (any inanimate object or substance capable of carrying infectious organisms). Consequently, the collective behaviour exhibited by the people led to a mass hysteria and eventually in the loss of social order. The society and the minds of people were 
filled with bafflement, outrage and helplessness. In Outbreak, the initial surfacing of the deadly virus was a military classified information where they incinerated an entire African village to hold on to the secret. But when the virus resurfaced in Zaire and then spread to the US, more people were involved as victims and also scientists trying to find a cure to the disease.

Along with the pandemic, fear had also spread among the people. These movies document the attempts of researchers to find a cure and the plight of people to receive the cure (where cure/vaccine is applicable). Through these movies we also see how researchers were trying to accommodate a new pathogen into the medical research. It was also the time when science failed to find a cure. Being a pandemic, nobody knew where it was spreading. In other words, a complete lack of information further intensified the chaos in society.

Contagion has no single protagonist or antagonist. Rather it is story of an initial outbreak of a pandemic, attempts to prevent it, the panic and decay of the social order and the final introduction of a vaccine. Meningoencephalitis Virus One (MEV-1) is a fictitious highly lethal virus that appears in the movie. It is portrayed as one among the most infectious agents that are spread through fomites. When a panic stricken crowd was in the midst of death and the government unable to determine a way out, there were also profiteers trying to reap gold.

This film has an ensemble cast and multiple plotlines that intersect at various points of the narrative. It begins with Beth Emhoff a businesswoman returning home to Minneapolis from Hong Kong with a cough and a headache. She gives her credit card to a bartender passing on the virus to him. The film shows similar cases in multiple places around the world. When Beth arrives home she hugs her son, Clark passing on the virus to him also. Within two days, after a 
seizure she dies and doctors were unable to determine the cause of death. Clark also dies with a similar condition. Before her husband Mitch Emhoff could come in terms with his grief the disease had spread across the globe. Somehow it was identified that he was born with an immune gene. The Emhoffs in the story is very intense as they represent the common man who is left at the mercy of the officials and social anarchy to save his daughter who may or may not have inherited his immune genes. He desperately wanted to save his daughter even if it meant locking her up in the house and detaching her from all possible social contacts.

The three doctors in the movie with their brief appearances also make substantial contributions to the development of the plot. The Centre for Disease Control and Prevention makes a guess that the disease is a bioweapon. Dr Erin Mears begins the investigation and she traces the outbreak back to Beth. However, during the course of her investigation she gets infected by the same and dies. Dr Leonora Orantes, a WHO epidemiologist is send to Hong Kong to trace the origins of the infection. As the virus spreads, Orantes is kidnapped and is used as leverage to obtain the first batch of vaccines. The character of Dr Ellis Cheever is torn between his principles of official duty and a personal transgression for his loved one. In the midst of all this there is a rogue blogger Alan Krumwiede who chooses to question everyone in the drama. His interventions throw light on the provocative deals between the government and pharmaceutical companies.

The conspirator in Krumwiede is also portrayed in the movie. He posts videos about the disease and in one of them appear to be sick. He claims to have recovered after using a homeopathic treatment. But later it was revealed that he was only trying to boost the demand and profit for investors in alternative medicine. He was arrested for fraud and conspiracy but was released 
when his blog readers collected and paid his bail. The role of Krumwiede is carried out through a social media (blogging/internet). Social media further stands out in the movie when the Emhoff's daughter carries on a relationship with her boyfriend through text messaging.

The social tension and hostility works out in different levels. People went berserk due to fear and lack of security. The use of bar-coded wristbands to identify the inoculated highlight the complex tensions between freedom and order. These wristbands along with offering the clearance of being inoculated also affected one's freedom of movement and mixing.

Outbreak on the other hand has a clear number of actors and lack interconnected plotlines. The deadly virus is called Motaba virus, which has a mutated strain when it resurfaced for the second time. What makes the movie different from Contagion is the fact that Motaba virus had a cure and it was kept under the covers so that it can be converted into a bioweapon. This movie also follows the traditional single hero plotline where he becomes responsible for saving the nation.

MEV-1 and Motaba are not lab-bred viruses. Both Contagion and Outbreak dramatize the outbreak of the virus as a result of human encroachment into the living ecosystem of animals. In Contagion a man with his bulldozer brings down a palm tree which had the nest of bats. The bats once they lose their ecosystem drop a chunk of half eaten banana into a pig pen. It is eaten by a pig and MEV-1 emerges as a bat-pig hybrid virus. Motaba virus is also traced back to a monkey which is the host animal. The monkey, a white headed capuchin was illegally brought to US into a biotest animal holding facility. Thus in both these cases, there is an uninvited entry of strangers (human beings) into a closed ecosystem of animals. According to Priscilla Wald, 
the construction of a new road to the jungle in Outbreak, stands as the marker of a foreign strain intervening in the habitation of a group of people. "... the virus emerges as a result of an ill mixing of cultures ... the local doctor does not dispute the belief of the only uninfected inhabitant of the village- the juju man who won't communicate with foreigners- that the virus is a punishment for the intrusion on the jungle that the road represents" (Wald 66-67).

MEV-1 and Motaba could transgress national boundaries. The viruses do not see the borders set up by human beings. Instead they announce the fluidity of the borders and its interconnected nature. As Wald proposes, "the human contact materialized by the spread of a communicable disease reveals an interactive and interconnected world. It makes visible the nature of those exchanges that are often concealed; communicable disease offers records of desire, of violence, of sexual commerce, all of which are especially apparent in sexually transmitted diseases" (38). In other words, a contagion has a vocabulary of its own and thereby it reveals certain social interactions that might be hidden from the general public's knowledge. In Contagion, Mitch Emhoff comes to know from CDC that his wife was cheating on him as her previous lover also died of the same virus. Mitch may not have come to know about it if it was not for the MEV-1. Wald puts this more appropriately as, "microbes tell the often hidden story of who has been where and when, and of what they did there" (37).

The disruption of the social order is also characterized by a specific pattern of the 'outbreak narrative'. The outbreak narrative starts with an initial anonymity of the virus and random deaths happening around the world. This makes the scientists to realise whether the outbreak is a pandemic or an endemic condition. Along with the emerging infection, the panic stricken citizens of the world create more chaos primarily because they have no clue about what is 
happening. In this pattern of the narrative, certain recurring images play an important role- the hunt for patient zero, host body, carrier, vaccine, serum, civilian rights, military curfew etc. These images/characters are more like the constituents of an outbreak formula. Following a painstaking struggle to find a vaccine for the virus by the scientists, the narrative ends with the final containment of the disease. Such an outbreak narrative is also interspersed with themes like animal rights, biological warfare, viruses versus immune humans, anti-corporate agenda (multi-national company funding the creation of viruses) etc.

\section{(Un)dead Bodies and New Humans}

\section{"Mankind has an expiration date"- Doomsday (2008) Poster}

Health continues to be the single most threatening concern of the human body. The body tries to adapt to the various needs of Nature and its changes. It might use vaccines to immunise itself from deadly diseases or it might modify itself into different forms- modified organisms that can survive more effectively. The question is what kinds of modifications are to be expected and allowed or are such decisions in our hands at all? Genetic mutation could be induced and its effects will be confined to a specific group of people creating hierarchies similar to all civilisations. But a genetic evolution is imminent for the creation of 'new humans'. It will only mark the human tendency and ability to survive during difficult times. A recent article in Huffington Post suggests that the myth of survival of the fittest is not applicable anymore as we have outsmarted the 'struggle' to survive with our advanced technology, agriculture and medicine. Unfortunately, the collective myth of Earth being ours and we being the masters of 
Earth has destroyed the Nature's own checks and balances. What Daniel Levine suggests in his article, "Extinction and the New Human" sounds appropriate to the present scenario:

humans too have become rigid, intractible in our reliance upon outmoded technologies (gasoline-powered cars, coal-burning power plants) which are poisoning our atmosphere. Our rigidity derives from our gigantic group size--big things have a hard time changing direction--but also from our complacency, our enslavement to convenience and comfort, our refusal to give up what we've gotten used to. Reconsideration requires stepping back, sometimes scaling down--and we have become addicted to dogged progress, to growth for its own sake (Levine).

Thus bodily modifications and enhancements are very often associated with eschatology. End of the world situations are generally signalled in cinema through alien invasion, spread of a deadly virus, disaster diseases like the plague, natural calamities like tsunami, famine, flood etc, a biowar went out of control, infected animal/carrier let lose by accident, harmful meteorite shower etc. Among these reasons for apocalypse, the fictional zombies or the 'living dead' forms of the human body are very popular in Hollywood cinema. Such (un)dead forms as found in Juan Carlos Fresnadillo's 28 Weeks Later (2007) and Marc Forster's World War Z (2013) represent the residents of a post apocalyptic world. Such infected forms are the majority in that new world and they stroll down the streets with a powerful urge to spread the virus. The compulsion to spread the virus is the inherent nature of the virus itself. The virus does not hide, but rather it is in the look out for healthier bodies.

In World War Z, we are treated with a plotline where a former UN investigator Gerry Lane (played by Brad Pitt) has to accompany a virologist, Andrew Fassbach to find a cure for the zombie pandemic. As the virologist gets killed in between by a zombie attack, Gerry Lane becomes the reluctant leader who has to carry on the rest of the work. Like many other sci-fi 
movies, the boldness and heroism of one man saves humanity from extinction. This movie introduces us to ideas like as a pathogen requires a healthy body for spreading the disease; a hungry pathogen will avoid a diseased body. This becomes an important cue in finding a cure for the zombie virus. A conversation that happened between the virologist and Gerry helps Gerry suggest a cure for the virus:

Mother Nature is a serial killer. No one's better, more creative. Like all serial killers, she can't help but the urge to want to get caught. But what good are all those brilliant crimes if no one takes the credit? So she leaves crumbs. Now the hard part, while you spent decades in school, is seeing the crumbs for the clues they are. Sometimes the thing you thought was the most brutal aspect of the virus, turns out to be the chink in its armor. And she loves disguising her weaknesses as strengths. She's a bitch (Forster).

Those 'crumbs' turn out to be the fact that the zombies do not attack seriously ill people. In other words, the viruses wanted healthy bodies for preying upon to survive and in effect creating more victims.

28 Weeks Later presents the outbreak of Rage virus. The incubation period of this virus is very short and thus once you are bitten by an infected person, you succumb to uncontrollable rage immediately, which is the mark of infection. While this movie is centered around one family, where the father character, Don becomes the first to be infected it is revealed that his wife, Alice who is also a carrier of the virus is immune to the Rage virus due to her unique genetic traits. This movie is a post-apocalyptic horror click and it does not end with the containment of the virus. The audience is left with a clue to how a vaccine could be made, but no cure is invented in the movie narrative. Rage virus continues to spread infecting and killing more number of people. 
In these movies, it is not one villain challenging people, but the whole of humanity itself is infected and the urge to spread the pathogen is very strong. Also, the traditional divine intervention of God punishing mankind is removed completely in these narratives. God-human binary is replaced by human versus human. The divine 'other' is superseded by something human-like, as in the zombies. The zombies look like humans with its body, two hands and two legs. They walk on two legs. But they are gory to look at and they feed on the flesh of the living. This paper proposes that these 'living dead' forms can be considered as the binary opposite of the genetically evolved beings or the new humans. What is more interesting in these movies is the characteristic feature of the above said human-like forms (zombies). As mentioned earlier, the urge of the infected people to spread the virus is alarming. Humans become excessively self-destructive. The fear of dehumanization and human extinction are reevoked in these narratives.

\section{Conclusion}

Through this paper I have presented the equation of health as represented in select Hollywood cinema. The human body continues to be the single most accessible space for conducting experimentations for betterment and also to be used as a weapon for mass destruction. As body modifications, genetic evolutions and other mediations are taking humanity towards a mutant epoch, popular media is no more interested in representing 'how' the world is going to end or 'if' the world is going to end or not. It is more concerned about depicting how best the individual agency can survive in a post-apocalyptic situation. Most commonly, as Conrad Ostwalt observes in his article titled, “Armageddon at the Millennial Dawn”, “... today's cinematic apocalyptic vision places humanity in an all too familiar precarious position, only to 
offer comfort and hope that human splendidness (in most cases American masculine splendidness) will rise to defeat dark or dangerous forces that seek to destroy us" (Ostwalt). However, it is crucial to remember that these representations in Hollywood cinema reflect our introspections about human interactions and the next Black Death.

\section{BIBLIOGRAPHY}

28 Weeks Later. Dir. Juan Carlos Fresnadillo Perf. Robert Carlyle, Rose Byrne and Jeremy Renner. $20^{\text {th }}$ Century Fox, 2007

Cavallaro, Dani. The Body for Beginners. New York: Writers and Readers, 1998. Print.

Contagion. Dir Steven Soderbergh. Perf. Kate Winslet, Jude Law, Matt Damon, Laurence Fishburne and Gwyneth Paltrow. Warner Bros, 2011.

Frank, Lawrence K. "What is Social Order?” American Journal of Sociology, Vol. 49, No. 5 (Mar. 1944), 470-477

Frow, John. "Bodies in Pieces." Cross/Cultures 33: The Body in the Library. Ed. Leigh Dale and Simon Ryan. Atlanta: Rodopi, 1998. 35-54. Print.

Levine, Daniel. "Extinction and the New Human”. Huffington Post. Web 29 May 2014.

Mott, Maryann. "Animal-Human Hybrids Spark Controversy." Daily Nature and Science News and Headlines | National Geographic News. Web. 19 Apr. 2011.

Nandy, Ashis. "Modern Medicine and Its Nonmodern Critics: A Study in Discourse." The Savage Freud and Other Essays in Possible and Retrievable Selves. New Delhi: Oxford UP, 1995. 145-95. Print. 
Ostwalt, Conrad “Armageddon at the Millennial Dawn”. Journal of Religion and Film. Vol. 4, No.1 (April 2000). Web 29 May 2014.

Outbreak. Dir Wolfgang Petersen. Perf. Dustin Hoffman, Rene Russo and Morgan Freeman. Warner Bros, 1995

Shaw, Ian and Alan Aldridge. "Consumerism, Health and Social Order”. Social Policy and Society. UK:CUP, 2003. 35-43. Print.

"The Vacanti Mouse: Gross and Incredible." Welcome to California Lutheran High School. Web. 19 Apr. 2011.

Wald, Priscilla. Contagious: Cultures, Carriers, and the Outbreak Narrative. US:Duke Univesrity Press, 2008. Print

World War Z. Dir. Marc Forster. Perf. Brad Pitt, Dede Gardner and Ian Bryce. Paramount Pictures, 2013. 